\title{
Mechanisms of the 14-3-3 Protein Function: Regulation of Protein Function Through Conformational Modulation
}

\author{
V. OBSILOVA ${ }^{1}$, M. KOPECKA ${ }^{1}$, D. KOSEK ${ }^{1,2}$, M. KACIROVA ${ }^{1,2}$, S. KYLAROVA ${ }^{1,2}$, \\ L. REZABKOVA ${ }^{1,2}$, T. OBSIL ${ }^{1,2}$ \\ ${ }^{1}$ Department of Protein Structure, Institute of Physiology Academy of Sciences of the Czech \\ Republic, Prague, Czech Republic, ${ }^{2}$ Department of Physical and Macromolecular Chemistry, \\ Faculty of Science, Charles University, Prague, Czech Republic
}

Received August 30, 2013

Accepted September 12, 2013

\begin{abstract}
Summary
Many aspects of protein function regulation require specific protein-protein interactions to carry out the exact biochemical and cellular functions. The highly conserved members of the 14-3-3 protein family mediate such interactions and through binding to hundreds of other proteins provide multitude of regulatory functions, thus playing key roles in many cellular processes. The 14-3-3 protein binding can affect the function of the target protein in many ways including the modulation of its enzyme activity, its subcellular localization, its structure and stability, or its molecular interactions. In this minireview, we focus on mechanisms of the 14-3-3 protein-dependent regulation of three important 14-3-3 binding partners: yeast neutral trehalase Nth1, regulator of G-protein signaling 3 (RGS3), and phosducin.
\end{abstract}

\section{Key words}

14-3-3 protein • Regulator of G-protein signalling (RGS3) • Phosducin • Neutral trehalase $\bullet$ Bmh1 • Conformation • Signaling

\section{Corresponding authors}

T. Obsil, Department of Physical and Macromolecular Chemistry, Faculty of Science, Charles University, Hlavova 2030, 12843 Prague, Czech Republic. E-mail: obsil@natur.cuni.cz and V. Obsilova, Institute of Physiology, Academy of Sciences of the Czech Republic, v.v.i., Videnska 1083, 14220 Prague, Czech Republic. E-mail: obsilova@biomed.cas.cz

\section{Introduction}

The 14-3-3 proteins are a family of highly conserved acidic $30 \mathrm{kDa}$ molecules that form stable homo- and heterodimers (Liu et al. 1995, Xiao et al. 1995). Each monomer consists of a bundle of nine antiparallel $\alpha$-helices and the 14-3-3 protein dimer possesses a characteristic cup-like shape with a large central channel containing two amphipathic binding grooves (Fig. 1). The inner walls of the central channel and the dimer interface are form by conserved residues whereas the less conserved residues are located on the outer convex surface. The extensive interactions between $\alpha$-helices make the structure of the 14-3-3 protein dimer highly rigid and only small differences between apo- and ligand-bound forms were observed (reviewed by Obsil and Obsilova 2011). This structural rigidity suggests that the 14-3-3 protein can behave as a rigid platform on which the bound target protein can be reshaped (Yaffe 2002). The most flexible region of the 14-3-3 protein molecule is the C-terminal segment which also exhibits highest sequence variability among the 14-3-3 isoforms. This region, due to its flexibility and the presence of negatively charged residues, has been shown to play an important role in the regulation of binding properties of the 14-3-3 protein isoforms (Truong et al. 2002, Obsilova et al. 2004, Silhan et al. 2004, Veisova et al. 2010). 
A

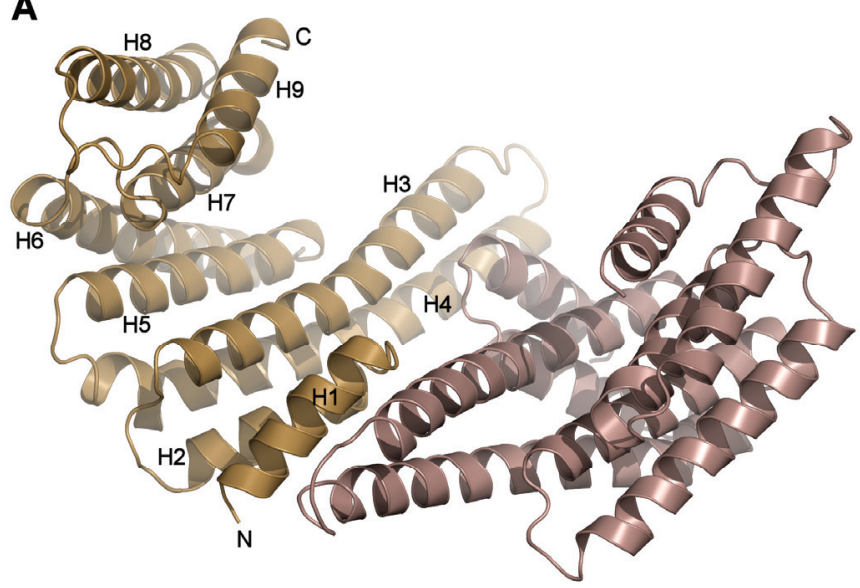

B

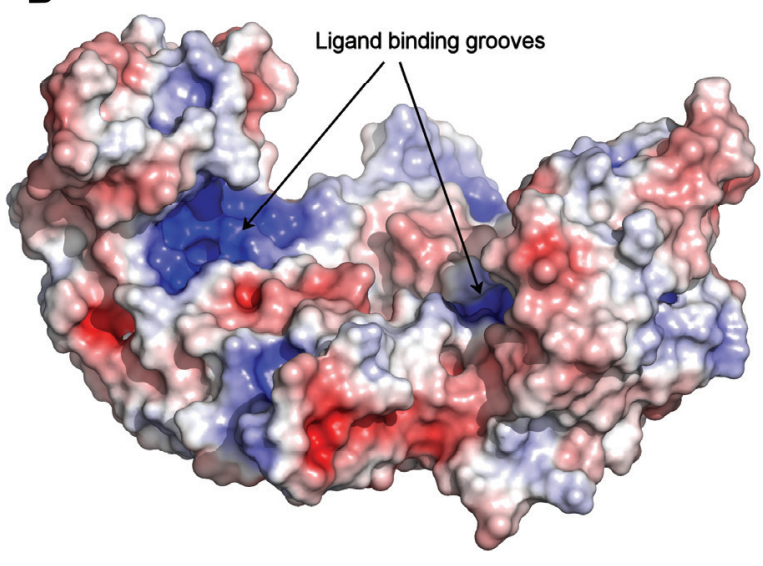

Fig. 1. Structure of the $14-3-3$ protein. (A) The ribbon representation of the crystal structure of the 14-3-3 $\zeta$ protein dimer (Obsil et al.

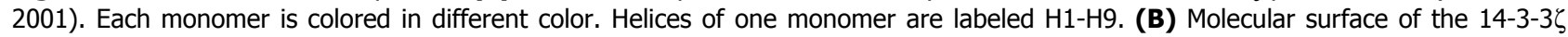
protein dimer. The surface is colored according to the electrostatic potential, ranging from $-6 \mathrm{kT} / \mathrm{e}$ (red) to $+6 \mathrm{kT} / \mathrm{e}$ (blue). The electrostatic potential was calculated using APBS package (Baker et al. 2001) and the figure was created using PyMOL (www.pymol.org). Arrows indicate the position of the ligand binding grooves.

The 14-3-3 proteins specifically recognize phosphoserine/phosphothreonine-containing motifs (Muslin et al. 1996). Three types of consensus 14-3-3 binding motifs were identified: $\mathrm{R}[\mathrm{S} / \Phi][+] \mathrm{pSXP}$ (mode I), $\mathrm{RX}[\Phi / \mathrm{S}][+] \mathrm{pSXP}$ (mode II), and pS- $\mathrm{X}_{1-2}-\mathrm{COOH}$ (motif III) where $\mathrm{pS}$ is phosphoserine (the phosphorylated residue may also be a threonine), $\Phi$ is an aromatic residue, + is a basic residue, and $\mathrm{X}$ is any type of residue (Yaffe et al. 1997, Rittinger et al. 1999, Ganguly et al. 2005). These motifs are not absolute as a number of the 14-3-3 protein binding partners identified to date contain either phosphorylated or even not-phosphorylated sequences that significantly differ from these optimal motifs (Masters et al. 1999, Wang et al. 1999, Johnson et al. 2010).

The mechanism of the 14-3-3 protein function can be generally classified into three modes of action: (1) direct conformational change of the target protein; (2) physical occlusion of sequence-specific or structural features; and (3) scaffolding that anchors proteins within close proximity of one another (reviewed by Fu et al. 2000, Tzivion and Avruch 2002, Bridges and Moorhead 2004, Obsil and Obsilova 2011). The exact mechanisms behind these modes are still mostly elusive, mainly due to the absence of high-resolution structures of the corresponding 14-3-3 protein complexes. This minireview focuses on mechanisms of the 14-3-3 protein-dependent regulation of three important 14-3-3 binding partners studied in our laboratory: (i) the yeast neutral trehalase Nth1; (ii) the regulator of G-protein signaling 3 (RGS3); and (iii) phosducin (Pdc). While Nth1 is an enzyme that catalyzes the hydrolysis of trehalose and its 14-3-3-dependent regulation seems to be an example of mode 1 mechanism (direct structural change), RGS3 and Pdc are proteins involved in the regulation of G-protein signaling and both of them seem to be regulated by a mechanism that includes both modes 1 and 2 (structural change accompanied by physical occlusion of the binding surface).

\section{The 14-3-3 protein-dependent activation of yeast neutral trehalase Nth1}

The neutral trehalase Nth1 belongs to the Glycoside hydrolase family 37 (EC 3.2.1.28) of O-Glycosyl hydrolases (EC 3.2.1.) which includes enzymes with the mutual trehalase activity (App and Holzer 1989, Kopp et al. 1993). Trehalase hydrolyzes disaccharide trehalose [ $\alpha$-D-glucopyranosyl-(1-1)- $\alpha$-Dglucopyranoside] into two glucose subunits monitoring the stable trehalase concentration by that way. Trehalose, as a non-reducing disaccharide of glucose functions as a storage carbohydrate and stress metabolite because its concentration increases during various adverse environmental conditions like dehydration, heat, cold, oxidation and desiccation. In yeast and plants it also may serve as a regulatory or signaling molecule, to control certain metabolic pathways or even to affect growth (Elbein et al. 2003). It has been shown that in the yeast Saccharomyces cerevisiae, Nth1 can be fully activated by the cAMP-dependent protein kinase (PKA) phosphorylation, $\mathrm{Ca}^{2+}$ ions and yeast 14-3-3 protein binding (Panni et al. 2008, Veisova et al. 2012). 
Bmh1 and Bmh2 (yeast 14-3-3 protein isoforms), share a great degree of homology and participate in the regulation of crucial physiological processes (van Heusden and Yde Steensma 2006, Veisova et al. 2010). Many interaction partners of the 14-3-3 proteins are phosphorylated on multiple amino acid residues and very often two phosphorylated motifs can be simultaneously involved in the interaction (Yaffe 2002). Nth1 is phosphorylated by PKA on multiple sites and phosphorylated Nth1 (pNth1) then interacts with Bmh proteins leading to the enhancement of pNth1 activity through an unknown mechanism (Panni et al. 2008). The identity and the role of individual PKA phosphorylation sites remain unclear. Thevelein group has recently shown using phosphospecific antibodies that glucose and nitrogen activation of trehalase in vivo is associated with phosphorylation of Ser21 and Ser83 (Schepers et al. 2012). It must be noted, however, that in this study phosphospecific antibodies just for pSer21 and pSer83 were used because the anti-pSer20 and anti-pSer60 couldn't properly recognize between phosphorylated and not-phosphorylated forms of Nth1. Additional regulatory mechanism (beyond Bmh stimulation) for activation of trehalase in vivo have also been identified (De Mesquita et al. 2003). Dcs1, an mRNA decapping enzyme, acts as the negative regulator of trehalase activity and thus prevents Nth1 from the 14-3-3 protein binding. The deletion of the inhibitor Dcs1 causes the activation and phosphorylation of Nth1 but the deletion of both Bmh1 and Bmh2 abolishes the Nth1 phosphorylation and activation (Schepers et al. 2012).

Our group has recently shown by MALDI-TOF MS analysis that four serine residues from the disordered N-terminal part of yeast Nth1 (Ser20, Ser21, Ser60 and Ser83) are phosphorylated by PKA in vitro (Veisova et al. 2012). Consequent biochemical characterization of the 14-3-3 protein-dependent activation of pNth1 showed that both yeast 14-3-3 isoforms form stable complexes with pNth1 (with the molar stoichiometry 2:1) and substantially increase its enzymatic activity. Site-directed mutagenesis revealed that phosphorylation sites Ser60 and Ser83 are essential for $\mathrm{pNth} 1$ activation both in vitro and in vivo and very likely function as the 14-3-3 binding motifs (Fig. 2A). In addition, it has previously been suggested that $\mathrm{Ca}^{2+}$ ions form the indivisible component of the active trehalase (Franco et al. 2003). However, we observed much weaker activation of pNth1 in the presence of $\mathrm{Ca}^{2+}$-only compared with the 14-3-3dependent activation (Veisova et al. 2012).

In order to obtain structural insight into the mechanism of the 14-3-3-dependent activation of pNth1, we performed a biophysical study of the Bmh1-pNth1 complex using hydrogen/deuterium exchange coupled to mass spectrometry (HDX-MS) and circular dichroism spectroscopy (CD) (Macakova et al. 2013). The HDX-MS was used to characterize the binding interface between these two proteins and we showed that the Bmh1 protein binding to pNth1 affects the structural properties of several Nth1 regions: the N-terminal segment containing phosphorylation sites essential for $\mathrm{pNth} 1$ binding to $\mathrm{Bmh}$, the region 102-185 containing the $\mathrm{Ca}^{2+}$-binding domain (including peptide 102-110 whose change in deuteration kinetics upon the Bmhl binding is shown in Figure 2B), and several regions from the catalytic trehalase domain. For structural interpretation of HDX-MS data we mapped the Bmh1-induced changes in the deuteration kinetics of pNth1 on the structural model of its catalytic domain (sequence 295-721). Peptides for which we observed significant changes in their deuteration kinetics upon the Bmh1 binding are shown in Figure $2 \mathrm{C}$ in orange and, as can be noticed, these peptides surround the active site of the catalytic trehalase domain. In addition, CD spectroscopy revealed that the complex formation is accompanied by change in the protein's tertiary structure. On the basis of these data, we proposed a model depicting the possible mechanism of the 14-3-3 protein-dependent activation of pNth1 (Fig. 2A). The active site of Nth1 in the absence of Bmh is buried within the structure of the trehalase domain and the enzyme is catalytically inactive. Interaction between pNth1 and $\mathrm{Bmh}$ induces a conformational change within both the $\mathrm{Ca}^{2+}$-binding and the catalytic trehalase domains in the close proximity of the active site. We can speculate that this structural change increases the accessibility of the active site and leads to the pNth1 activation (Macakova et al. 2013). Our data also show that the interaction surface of the Bmh1 molecule in the Bmh1-pNth1 complex includes not only the surface of the ligand binding groove, where the phosphorylated N-terminal segment of $\mathrm{pNth} 1$ binds, but also the surfaces outside the central cavity of the Bmh1 dimer.

Thus, our proposed model for the 14-3-3 proteindependent activation of $\mathrm{pNth} 1$ seems to be an example of mode 1 mechanism and resembles the 14-3-3 proteindependent activation of serotonin $\mathrm{N}$-acetyltransferase (Obsil et al. 2001). In that case the 14-3-3 protein also enhances the enzymatic activity by binding to the phosphorylated form of the enzyme and inducing a structural change in close proximity of its active site but remote from the phosphorylated 14-3-3 binding motif. 

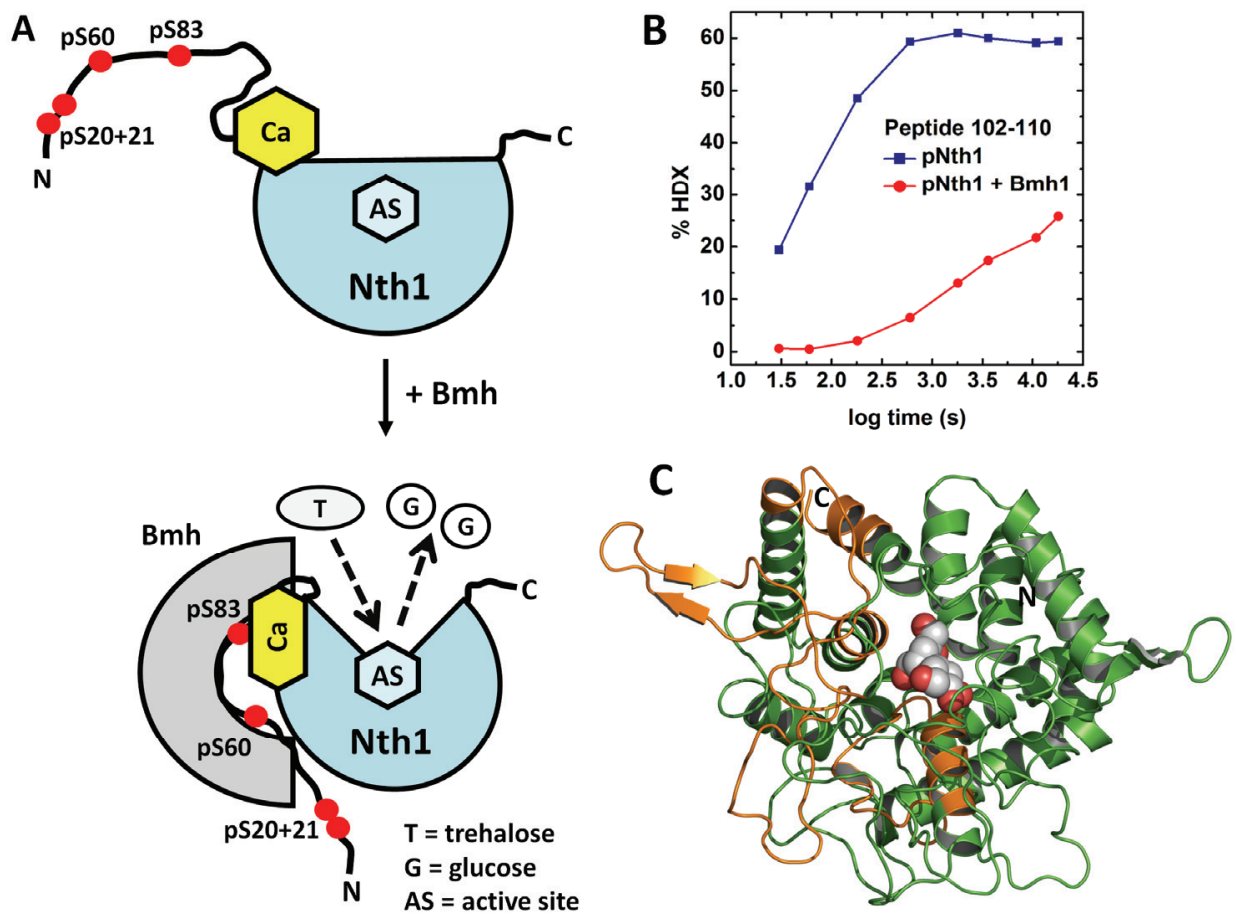

Fig. 2. Proposed mechanism for the Bmh-dependent activation of Nth1. (A) The active site of Nth1 in the absence of $\mathrm{Bmh}$ is buried within the structure of the trehalase domain and the enzyme is catalytically inactive (Macakova et al. 2013). Phosphorylated Nth1 is recognized by $\mathrm{Bmh}$ protein (yeast 14-3-3 isoform) and its binding to the $\mathrm{N}$-terminal pSer60 and pSer83 induces conformational change within both the $\mathrm{Ca}^{2+}$-binding domain and the catalytic domain in close proximity to the active site. This structural change enables substrate and product entry and departure, respectively, hence the enzyme activation. AS denotes the active site, $\mathrm{T}$ and $\mathrm{G}$ denote trehalose and glucose, respectively, serines that are phosphorylated by PKA are shown as red circles. The $\mathrm{Ca}^{2+}$-binding domain, the

catalytic trehalase domain and the Bmh protein are shown in yellow, cyan and grey, respectively. (B) The Bmh1-dependent decrease in the deuterium exchange kinetics for the peptide $102-110$ that surrounds the calcium binding domain. The deuteration kinetics is expressed as percentages relative to the maximum theoretical deuteration level for pNth1 alone (blue circles) and pNth1 in the presence of Bmh1 (red circles) after 10 minutes of deuteration. Time units are in seconds. (C) Homology model of the catalytic trehalase domain of Nth1 (sequence 295-721). Regions that show slower deuterium exchange kinetics upon the Bmh1 binding are shown in orange. The active site contains trehalase inhibitor validoxylamine (shown as spheres) based on the crystal structure of trehalase Tre37A (PDB code 2JF4) used as a template to build this homology model (Gibson et al. 2007).
A

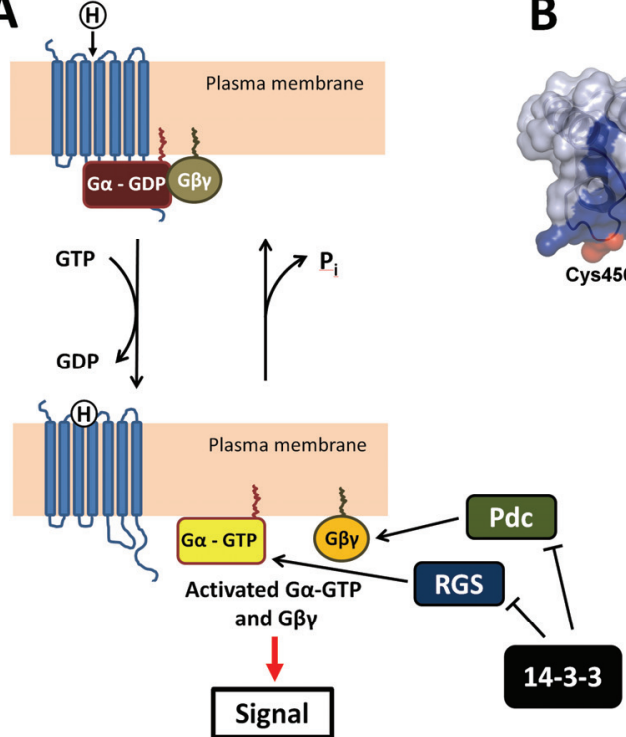

B

RGS domain

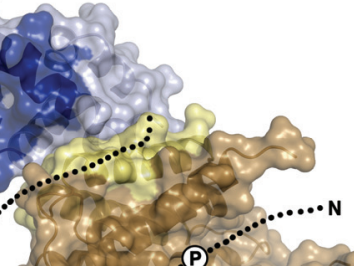

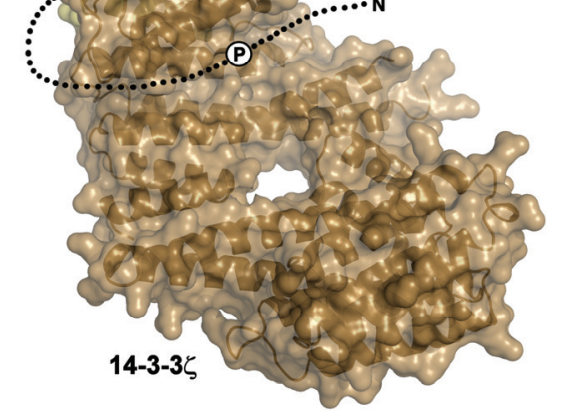

Fig. 3. Role of RGS3 and Pdc in the regulation of G-protein signaling. (A) Ligand binding, $\mathrm{H}$, to the G-protein coupled receptor (GPCR, shown in blue) induces a conformational change in the receptor, which is transduced to the inactive heterotrimeric G-protein $(G \alpha \beta \gamma)$. This enables the exchange of GDP for GTP on the $G \alpha$ subunit and the dissociation of now active $\mathrm{G} \alpha$ and G $\beta \gamma$ subunits (shown in yellow and orange, respectively) that can mediate downstream signals. The amplitude and duration of the signal is dependent on the rate of activation as well as the rate of inactivation through GTP hydrolysis. This process is accelerated by RGS proteins that increase the rate of GTP hydrolysis, thus returning the G-protein to its heterotrimeric GDP-bound inactive state (Jean-Baptiste et al. 2006). Pdc, on the other hand, regulates visual signal transduction by modulating the amount of transducin $\mathrm{G}_{t} \alpha \beta \gamma$ heterotrimer through competition with the $\mathrm{G}_{t} \alpha$ subunit for binding to the $\mathrm{G}_{\mathrm{t}} \beta \gamma$ complex (Bauer et al. 1992, Lee et al. 1987). Both RGS3 and Pdc are inhibited by means of the 14-3-3 protein binding. (B) The

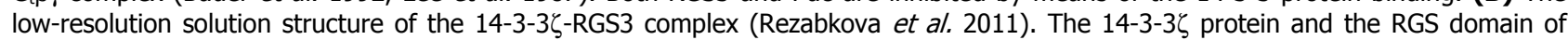
RGS3 are shown in brown and light blue, respectively. The Go interaction surface of the RGS domain is shown in dark blue. The less

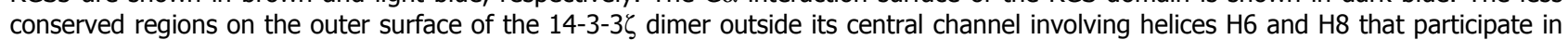
interaction with RGS3 are shown in light yellow. Residue Cys456 is shown in red. 
The 14-3-3 protein-dependent inhibition of the regulator of $G$-protein signaling 3 (RGS3)

The amplitude and duration of G-protein signaling are regulated at the G-protein level by two different mechanisms. The first one involves the enhancement of the low intrinsic GTPase activity of the Go subunit (Berman et al. 1996, Watson et al. 1996), whereas the second one is based on the inhibition of G $\beta \gamma$ interactions with G $\alpha$-GDP and downstream effectors (Lee et al. 1988, Willardson et al. 1996) (Fig. 3A). The first mechanism is carried out by a highly conserved regulator of G-protein signaling (RGS) domain of RGS proteins that specifically recognizes the GTP-bound form of $\mathrm{G} \alpha$ and function as GTPase-activating proteins (GAP) for $\mathrm{G} \alpha$ by stabilizing the transition state (Hepler et al. 1997, Tesmer et al. 1997). The RGS domain consists of $\sim 125$ amino acid residues and more than 25 proteins containing RGS or RGS homology domains have been identified to date. Some RGS proteins consist of little more that the RGS domain (e.g. RGS1, RGS2, RGS4) while others possess long N-terminal or C-terminal extensions (e.g. RGS3, RGS7, RGS9) that usually contain additional protein-protein interaction motifs and domains (Ishii and Kurachi 2003). Through these nonRGS regions RGS proteins can also serve many noncanonical functions distinct from inactivation of $\mathrm{G} \alpha$ (reviewed by Abramow-Newerly et al. 2006b, Sethakorn et al. 2010).

Various mechanisms are involved in the regulation of RGS functions including the posttranslational modifications and the interaction with other signaling proteins (Kim et al. 1999, Schiff et al. 2000, Roy et al. 2003). Certain RGS proteins, including RGS3-5, RGS7, RGS8, and RGS16, have been found to interact with various 14-3-3 isoforms (Benzing et al. 2000, 2002, Schreiber et al. 2001, Niu et al. 2002, Abramow-Newerly et al. 2006a). Some of these studies showed that the 14-3-3 protein binding inhibits GAP function of, at least, RGS4, RGS7 and RGS16 presumably by blocking RGS-G $\alpha$ interaction through unknown mechanism (Benzing et al. 2000, AbramowNewerly et al. 2006a). Two different 14-3-3 binding sites have been identified on RGS3 and RGS7. Benzing et al. (2000, 2002) suggested that the 14-3-3 binding site is located within the RGS domain at a conserved Ser-TyrPro motif. However, other studies showed that $\mathrm{Ser}^{264}$ of RGS3 located outside of its RGS domain serves as the primary 14-3-3 binding site (Niu et al. 2002, Ward and Milligan 2005). This residue is presumably phosphorylated by PKA, and its sequence $\left(\mathrm{R}^{259} \mathrm{RRTH} \underline{\mathrm{SEG}}{ }^{266}\right)$ is consistent with the type II binding motif for 14-3-3 (Yaffe et al. 1997). In addition, while phosphorylation of RGS3 and RGS7 has been shown to be required for their binding to 14-3-3 (Benzing et al. 2000, 2002), it seems that RGS4, RGS5 and RGS16 can interact with 14-3-3 in a phosphorylation-independent manner (Abramow-Newerly et al. 2006a).

RGS3 belongs to a B/R4 subfamily of RGS proteins and it has been shown that their interacting partners within GPCR pathways are $\mathrm{G} \alpha_{\mathrm{i}}, \mathrm{G} \alpha_{\mathrm{q}}$ and $\mathrm{G} \beta_{1} \gamma_{2}$ (Shi et al. 2001, 2002). While most members of this subfamily are relatively small and consist of only the RGS domain flanked by short N- and C-termini, two isoforms (splice variants) of RGS3, called RGS3L and PDZ-RGS3, contain large N-terminal extension (Kehrl et al. 2002). Niu et al. (2002) showed that the 14-3-3 protein binding to RGS3 phosphorylated at $\mathrm{Ser}^{264}$ within this N-terminal extension blocks the interaction between RGS3 and G-proteins. To investigate the mechanism by which 14-3-3 interferes with the RGS3-G-protein interaction, we used several biophysical methods to obtain structural insight into this interaction. The timeresolved tryptophan fluorescence of two RGS3 mutants containing single-Trp residue either at position 295 (within the $\mathrm{N}$-terminal extension close to the phosphorylation site $\mathrm{Ser}^{264}$ ) or at position 424 (within the RGS domain) revealed that the 14-3-3 $\zeta$ binding induces significant structural changes in the vicinity of both these residues (Rezabkova et al. 2010). This suggested that not only the region containing the phosphorylated 14-3-3 binding motif but also the remote C-terminally located RGS domain physically interact with the 14-3-3 dimer and/or undergoe a structural change upon the 14-3-3 $\zeta$-RGS3 complex formation. Since $\operatorname{Trp}^{424}$ is located in the center of the RGS domain close to its $\mathrm{G} \alpha$ interaction surface, it is reasonable to speculate this 14-3-3 protein binding-dependent structural change within the RGS domain could be responsible for the inhibition of RGS3-G $\alpha$ interaction.

To obtain a more detailed structural insight into the interaction between 14-3-3 $\zeta$ and RGS3, we next used small angle x-ray scattering (SAXS), hydrogen/deuterium exchange kinetics (HDX-MS), and Förster resonance energy transfer measurements to determine the lowresolution solution structure (hybrid structure) of the

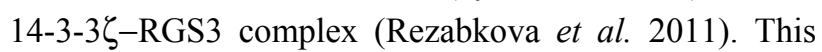


structural model revealed that the RGS domain of RGS3 interacts with less conserved regions on the outer surface of the 14-3-3 $\zeta$ dimer outside its central channel involving helices $\mathrm{H} 6$ and $\mathrm{H} 8$, thus providing a possible mechanistic explanation for the 14-3-3-dependent inhibition of RGS3 GAP function (Fig. 3B). The model suggests that the 14-3-3 $\zeta$ protein binding sterically occludes the RGS3-G $\alpha$ complex formation due to its binding in close proximity to the $\mathrm{G} \alpha$ binding interface of the RGS domain. In addition, the time-resolved AEDANS fluorescence measurements confirmed the results of tryptophan fluorescence experiments and showed that the 14-3-3 $\zeta$ protein binding changes the structure of the RGS domain within its $\mathrm{G} \alpha$-interacting portion (Rezabkova et al. 2011). The most significant 14-3-3 $\zeta$ binding-induced change in fluorescence was observed for AEDANS-labeled Cys ${ }^{456}$ located directly within the $\mathrm{G} \alpha$ interaction surface of the RGS domain (Fig. 3B). Thus, our results suggest that the 14-3-3 $\zeta$ protein binding affects the structure of the G $\alpha$ interaction portion of RGS3 as well as sterically blocks the interaction between the RGS domain and the G $\alpha$ subunit of heterotrimeric G-proteins.

\section{The 14-3-3 protein-dependent regulation of phosducin}

Phosducin (Pdc) is a highly conserved acidic phosphoprotein involved in the regulation of visual signal transduction, the transcriptional control, the regulation of transmission at the photoreceptor-to-ON-bipolar cell synapse, and the modulation of sympathetic activity and blood pressure (Lee et al. 1987, Bauer et al. 1992, Zhu and Craft 2000, Beetz et al. 2009, Herrmann et al. 2010). The best understood role of Pdc is the regulation of visual signal transduction by modulating of the amount of transducin $\mathrm{G}_{\mathrm{t}} \alpha \beta \gamma$ heterotrimer through competition with the $G_{t} \alpha$ subunit for binding to the $G_{t} \beta \gamma$ complex (Fig. 3A) (Lee et al. 1987, Bauer et al. 1992). The crystal structure of the Pdc- $\mathrm{G}_{\mathrm{t}} \beta \gamma$ complex showed that Pdc consists of two separate domains that wrap around $\mathrm{G}_{\mathrm{t}} \beta \gamma$ to form an extensive binding interface (Gaudet et al. 1996). The N-terminal domain seems to be highly flexible and partly disordered while the C-terminal domain possesses the thioredoxin-like fold. The stability of the Pdc- $G_{t} \beta \gamma$ complex is strongly dependent on the phosphorylation state of Pdc molecule as the phosphorylation of several serine residues within its $\mathrm{N}$-terminal domain reduces its binding affinity through a mechanism that is still unclear (Lee et al. 2004). The in vitro studies revealed that residue Ser73 is phosphorylated by PKA while residues Ser36, Ser54, Ser73, and Ser106 are targets of the $\mathrm{Ca}^{2+} /$ calmodulin-dependent protein kinase (CaMKII) (Lee et al. 1990, Thulin et al. 2001). However, only the phosphorylation of Ser54 and Ser73, that are both located within the N-terminal domain, seems to be involved in the regulation of Pdc function in vivo and it has been shown that Pdc phosphorylated at these two sites forms a stable complex with the 14-3-3 protein (Nakano et al. 2001, Thulin et al. 2001, Lee et al. 2004). The role of the 14-3-3 protein in the regulation of Pdc is still unclear. The 14-3-3 protein may completely block the interaction between Pdc and $G_{t} \beta \gamma$ by interacting and/or affecting the structure of the $G_{t} \beta \gamma$ binding surface within the $\mathrm{N}$-terminal domain of Pdc. Another possibility is that the 14-3-3 binding decreases the rate of Pdc dephosphorylation and/or degradation. The 14-3-3 protein binding could also modulate interactions between Pdc and its other binding partners the transcription factor CRX and a subunit of the $26 \mathrm{~S}$ proteasome complex SUG1 which were both reported to interact with the C-terminal domain of Pdc (Zhu and Craft 1998, 2000).

To better understand the interaction between Pdc and the 14-3-3 protein, we recently performed a biophysical analysis of the interaction between Pdc doubly phosphorylated at Ser54 and Ser73 and the 14-3-3 $\zeta$ isoform (Rezabkova et al. 2012). Analytical ultracentrifugation showed that the simultaneous phosphorylation of both Ser54 and Ser73 is important for the interaction between $\mathrm{Pdc}$ and $14-3-3 \zeta$ as well as that these two proteins form a complex with the 1:2 stoichiometry (one molecule of Pdc interacts with the 14-3-3 dimer). The combination of data from analytical ultracentrifugation and dynamic light scattering also suggested that the Pdc molecule binds to the central channel of the cup-shaped $14-3-3 \zeta$ dimer. The timeresolved AEDANS fluorescence spectroscopy experiments revealed that the $14-3-3 \zeta-P d c$ complex formation affects the structure and reduces the flexibility of both the N- and C-terminal domains of Pdc, although both 14-3-3 binding motifs are located within the $\mathrm{N}$-terminal domain. These structural changes involve the $\mathrm{G}_{\mathrm{t}} \beta \zeta$ binding region within the $\mathrm{N}$-terminal domain of Pdc, and thus could explain the inhibitory effect of 14-3-3 on Pdc- $G_{t} \beta \zeta$ interaction. In addition, the 14-3-3 bindinginduced structural change within the C-terminal domain of Pdc suggests that 14-3-3 might be involved in the modulation of its interactions with CRX and SUG1. 


\section{Conclusions}

Mechanisms of the 14-3-3 protein-dependent regulation of all three proteins mentioned in this minireview, Nth1, RGS3 and Pdc, show one common aspect - a conformational change induced by binding to the 14-3-3 protein molecule involving regions that are remote from the segment containing phosphorylated 14-3-3 binding motif(s). This confirms that the interactions between 14-3-3 and its ligand extend beyond those involving the ligand binding groove. HDX-MS experiments revealed that the 14-3-3 protein directly interacts with its binding partner using regions other than that of the central channel including the less conserved regions of helices $\mathrm{H} 6$ and $\mathrm{H} 8$ outside the central channel of the 14-3-3 dimer. The involvement of such less conserved regions may explain the observed isoformspecific interactions between 14-3-3 and their ligands. In addition, in the case of RGS3 as well as Pdc the 14-3-3 protein sterically blocks the binding surface of these proteins, thus inhibiting their interactions with other binding partners. In both cases these steric occlusions affect the same regions where we observed conformational changes (the N-terminal domain of Pdc and the RGS domain of RGS3).

\section{Conflict of Interest}

There is no conflict of interest.

\section{Acknowledgements}

The authors are supported by the Czech Science Foundation (projects P305/11/0708 and P207/11/0455); Ministry of Education, Youth, and Sports of the Czech Republic (research project MSM0021620857); and Academy of Sciences of the Czech Republic (research project RVO 67985823).

\section{References}

ABRAMOW-NEWERLY M, MING H, CHIDIAC P: Modulation of subfamily B/R4 RGS protein function by 14-3-3 proteins. Cell Signal 18: 2209-2222, 2006a.

ABRAMOW-NEWERLY M, ROY AA, NUNN C, CHIDIAC P: RGS proteins have a signalling complex: interactions between RGS proteins and GPCRs, effectors, and auxiliary proteins. Cell Signal 18: 579-591, $2006 \mathrm{~b}$.

APP H, HOLZER H: Purification and characterization of neutral trehalase from the yeast ABYS1 mutant. J Biol Chem 264: 17583-17588, 1989.

BAKER NA, SEPT D, JOSEPH S, HOLST MJ, MCCAMMON JA: Electrostatics of nanosystems: application to microtubules and the ribosome. Proc Natl Acad Sci USA 98: 10037-10041, 2001.

BAUER PH, MULLER S, PUZICHA M, PIPPIG S, OBERMAIER B, HELMREICH EJ, LOHSE MJ: Phosducin is a protein kinase A-regulated G-protein regulator. Nature 358: 73-76, 1992.

BEETZ N, HARRISON MD, BREDE M, ZONG X, URBANSKI MJ, SIETMANN A, KAUFLING J, BARROT M, SEELIGER MW, VIEIRA-COELHO MA, HAMET P, GAUDET D, SEDA O, TREMBLAY J, KOTCHEN TA, KALDUNSKI M, NUSING R, SZABO B, JACOB HJ, COWLEY AW JR, BIEL M, STOLL M, LOHSE MJ, BROECKEL U, HEIN L: Phosducin influences sympathetic activity and prevents stress-induced hypertension in humans and mice. J Clin Invest 119: 3597-3612, 2009.

BENZING T, YAFFE MB, ARNOULD T, SELLIN L, SCHERMER B, SCHILLING B, SCHREIBER R, KUNZELMANN K, LEPARC GG, KIM E, WALZ G: 14-3-3 interacts with regulator of G protein signaling proteins and modulates their activity. J Biol Chem 275: 28167-28172, 2000.

BENZING T, KOTTGEN M, JOHNSON M, SCHERMER B, ZENTGRAF H, WALZ G, KIM E: Interaction of 14-3-3 protein with regulator of $\mathrm{G}$ protein signaling 7 is dynamically regulated by tumor necrosis factor-alpha. $J$ Biol Chem 277: 32954-32962, 2002.

BERMAN DM, WILKIE TM, GILMAN AG: GAIP and RGS4 are GTPase-activating proteins for the Gi subfamily of G protein alpha subunits. Cell 86: 445-452, 1996.

BRIDGES D, MOORHEAD GB: 14-3-3 proteins: a number of functions for a numbered protein. Sci STKE 2004: re10, 2004.

DE MESQUITA JF, PANEK AD, DE ARAUJO PS: In silico and in vivo analysis reveal a novel gene in Saccharomyces cerevisiae trehalose metabolism. BMC Genomics 4: 45, 2003. 
ELBEIN AD, PAN YT, PASTUSZAK I, CARROLL D: New insights on trehalose: a multifunctional molecule. Glycobiology 13: 17R-27R, 2003.

FRANCO A, SOTO T, VICENTE-SOLER J, PAREDES V, MADRID M, GACTO M, CANSADO J: A role for calcium in the regulation of neutral trehalase activity in the fission yeast Schizosaccharomyces pombe. Biochem J 376: 209-217, 2003.

FU H, SUBRAMANIAN RR, MASTERS SC: 14-3-3 proteins: structure, function, and regulation. Annu Rev Pharmacol Toxicol 40: 617-647, 2000.

GANGUly S, WELLER JL, HO A, CHEMINEAU P, MALPAUX B, KLEIN DC: Melatonin synthesis: 14-3-3dependent activation and inhibition of arylalkylamine N-acetyltransferase mediated by phosphoserine-205. Proc Natl Acad Sci USA 102: 1222-1227, 2005.

GAUDET R, BOHM A, SIGLER PB: Crystal structure at 2.4 angstroms resolution of the complex of transducin betagamma and its regulator, phosducin. Cell 87: 577-588, 1996.

GIBSON RP, GLOSTER TM, ROBERTS S, WARREN RA, STORCH DE GRACIA I, GARCIA A, CHIARA JL, DAVIES GJ: Molecular basis for trehalase inhibition revealed by the structure of trehalase in complex with potent inhibitors. Angew Chem Int Ed Engl 46: 4115-4119, 2007.

HEPLER JR, BERMAN DM, GILMAN AG, KOZASA T: RGS4 and GAIP are GTPase-activating proteins for Gq alpha and block activation of phospholipase C beta by gamma-thio-GTP-Gq alpha. Proc Natl Acad Sci USA 94: 428-432, 1997.

HERRMANN R, LOBANOVA ES, HAMMOND T, KESSLER C, BURNS ME, FRISHMAN LJ, ARSHAVSKY VY: Phosducin regulates transmission at the photoreceptor-to-ON-bipolar cell synapse. $J$ Neurosci 30: 3239-3253, 2010.

ISHII M, KURACHI Y: Physiological actions of regulators of G-protein signaling (RGS) proteins. Life Sci 74: 163-171, 2003.

JEAN-BAPTISTE G, YANG Z, GREENWOOD MT: Regulatory mechanisms involved in modulating RGS function. Cell Mol Life Sci 63: 1969-1985, 2006.

JOHNSON C, CROWTHER S, STAFFORD MJ, CAMPBELL DG, TOTH R, MACKINTOSH C: Bioinformatic and experimental survey of 14-3-3-binding sites. Biochem J 427: 69-78, 2010.

KEHRL JH, SRIKUMAR D, HARRISON K, WILSON GL, SHI CS: Additional 5' exons in the RGS3 locus generate multiple mRNA transcripts, one of which accounts for the origin of human PDZ-RGS3. Genomics 79: $860-868,2002$.

KIM E, ARNOULD T, SELLIN L, BENZING T, COMELLA N, KOCHER O, TSIOKAS L, SUKHATME VP, WALZ G: Interaction between RGS7 and polycystin. Proc Natl Acad Sci USA 96: 6371-6376, 1999.

KOPP M, MULLER H, HOLZER H: Molecular analysis of the neutral trehalase gene from Saccharomyces cerevisiae. J Biol Chem 268: 4766-4774, 1993.

LEE BY, THULIN CD, WILLARDSON BM: Site-specific phosphorylation of phosducin in intact retina. Dynamics of phosphorylation and effects on G protein beta gamma dimer binding. J Biol Chem 279: 54008-54017, 2004.

LEE RH, LIEBERMAN BS, LOLLEY RN: A novel complex from bovine visual cells of a 33,000-dalton phosphoprotein with beta- and gamma-transducin: purification and subunit structure. Biochemistry 26: 3983-3990, 1987.

LEE RH, WHELAN JP, LOLLEY RN, MCGINNIS JF: The photoreceptor-specific $33 \mathrm{kDa}$ phosphoprotein of mammalian retina: generation of monospecific antibodies and localization by immunocytochemistry. Exp Eye Res 46: 829-840, 1988.

LEE RH, BROWN BM, LOLLEY RN: Protein kinase A phosphorylates retinal phosducin on serine 73 in situ. $J$ Biol Chem 265: 15860-15866, 1990.

LIU D, BIENKOWSKA J, PETOSA C, COLLIER RJ, FU H, LIDDINGTON R: Crystal structure of the zeta isoform of the 14-3-3 protein. Nature 376: 191-194, 1995.

MACAKOVA E, KOPECKA M, KUKACKA Z, VEISOVA D, NOVAK P, MAN P, OBSIL T, OBSILOVA V: Structural basis of the 14-3-3 protein-dependent activation of yeast neutral trehalase Nth1. Biochim Biophys Acta 1830: 4491-4499, 2013. 
MASTERS SC, PEDERSON KJ, ZHANG L, BARBIERI JT, FU H: Interaction of 14-3-3 with a nonphosphorylated protein ligand, exoenzyme S of Pseudomonas aeruginosa. Biochemistry 38: 5216-5221, 1999.

MUSLIN AJ, TANNER JW, ALLEN PM, SHAW AS: Interaction of 14-3-3 with signaling proteins is mediated by the recognition of phosphoserine. Cell 84: 889-897, 1996.

NAKANO K, CHEN J, TARR GE, YOSHIDA T, FLYNN JM, BITENSKY MW: Rethinking the role of phosducin: light-regulated binding of phosducin to 14-3-3 in rod inner segments. Proc Natl Acad Sci USA 98: 4693-4698, 2001.

NIU J, SCHESCHONKA A, DRUEY KM, DAVIS A, REED E, KOLENKO V, BODNAR R, VOYNOYASENETSKAYA T, DU X, KEHRL J, DULIN NO: RGS3 interacts with 14-3-3 via the N-terminal region distinct from the RGS (regulator of G-protein signalling) domain. Biochem J 365: 677-684, 2002.

OBSIL T, GHIRLANDO R, KLEIN DC, GANGULY S, DYDA F: Crystal structure of the 14-3-3zeta: serotonin N-acetyltransferase complex: a role for scaffolding in enzyme regulation. Cell 105: 257-267, 2001.

OBSIL T, OBSILOVA V: Structural basis of 14-3-3 protein functions. Semin Cell Dev Biol 22: 663-672, 2011.

OBSILOVA V, HERMAN P, VECER J, SULC M, TEISINGER J, OBSIL T: 14-3-3zeta C-terminal stretch changes its conformation upon ligand binding and phosphorylation at Thr232. J Biol Chem 279: 4531-4540, 2004.

PANNI S, LANDGRAF C, VOLKMER-ENGERT R, CESARENI G, CASTAGNOLI L: Role of 14-3-3 proteins in the regulation of neutral trehalase in the yeast Saccharomyces cerevisiae. FEMS Yeast Res 8: 53-63, 2008.

REZABKOVA L, BOURA E, HERMAN P, VECER J, BOUROVA L, SULC M, SVOBODA P, OBSILOVA V, OBSIL T: 14-3-3 protein interacts with and affects the structure of RGS domain of regulator of $\mathrm{G}$ protein signaling 3 (RGS3). $J$ Struct Biol 170: 451-461, 2010.

REZABKOVA L, MAN P, NOVAK P, HERMAN P, VECER J, OBSILOVA V, OBSIL T: Structural basis for the 14-3-3 protein-dependent inhibition of the regulator of G protein signaling 3 (RGS3) function. $J$ Biol Chem 286: 43527-43536, 2011.

REZABKOVA L, KACIROVA M, SULC M, HERMAN P, VECER J, STEPANEK M, OBSILOVA V, OBSIL T: Structural modulation of phosducin by phosphorylation and 14-3-3 protein binding. Biophys $J$ 103: 1960-1969, 2012.

RITTINGER K, BUDMAN J, XU J, VOLINIA S, CANTLEY LC, SMERDON SJ, GAMBLIN SJ, YAFFE MB: Structural analysis of 14-3-3 phosphopeptide complexes identifies a dual role for the nuclear export signal of 14-3-3 in ligand binding. Mol Cell 4: 153-166, 1999.

ROY AA, LEMBERG KE, CHIDIAC P: Recruitment of RGS2 and RGS4 to the plasma membrane by G proteins and receptors reflects functional interactions. Mol Pharmacol 64: 587-593, 2003.

SETHAKORN N, YAU DM, DULIN NO: Non-canonical functions of RGS proteins. Cell Signal 22: 1274-1281, 2010.

SHI CS, LEE SB, SINNARAJAH S, DESSAUER CW, RHEE SG, KEHRL JH: Regulator of G-protein signaling 3 (RGS3) inhibits Gbetalgamma 2-induced inositol phosphate production, mitogen-activated protein kinase activation, and Akt activation. $J$ Biol Chem 276: 24293-24300, 2001.

SHI GX, HARRISON K, WILSON GL, MORATZ C, KEHRL JH: RGS13 regulates germinal center B lymphocytes responsiveness to CXC chemokine ligand (CXCL)12 and CXCL13. J Immunol 169: 2507-2515, 2002.

SCHEPERS W, VAN ZEEBROECK G, PINKSE M, VERHAERT P, THEVELEIN JM: In vivo phosphorylation of Ser21 and Ser83 during nutrient-induced activation of the yeast protein kinase A (PKA) target trehalase. $J$ Biol Chem 287: 44130-44142, 2012.

SCHIFF ML, SIDEROVSKI DP, JORDAN JD, BROTHERS G, SNOW B, DE VRIES L, ORTIZ DF, DIVERSEPIERLUISSI M: Tyrosine-kinase-dependent recruitment of RGS12 to the N-type calcium channel. Nature 408: 723-727, 2000.

SCHREIBER R, KINDLE P, BENZING T, WALZ G, KUNZELMANN K: Control of the cystic fibrosis transmembrane conductance regulator by alphaG(i) and RGS proteins. Biochem Biophys Res Commun 281: 917-923, 2001.

SILHAN J, OBSILOVA V, VECER J, HERMAN P, SULC M, TEISINGER J, OBSIL T: 14-3-3 protein C-terminal stretch occupies ligand binding groove and is displaced by phosphopeptide binding. J Biol Chem 279: 4911349119, 2004. 
TESMER JJ, BERMAN DM, GILMAN AG, SPRANG SR: Structure of RGS4 bound to AlF4--activated G(i alpha1): stabilization of the transition state for GTP hydrolysis. Cell 89: 251-261, 1997.

THULIN CD, SAVAGE JR, MCLAUGHLIN JN, TRUSCOTT SM, OLD WM, AHN NG, RESING KA, HAMM HE, BITENSKY MW, WILLARDSON BM: Modulation of the $G$ protein regulator phosducin by $\mathrm{Ca} 2+/$ calmodulin-dependent protein kinase II phosphorylation and 14-3-3 protein binding. $J$ Biol Chem 276: 23805-23815, 2001.

TRUONG AB, MASTERS SC, YANG H, FU H: Role of the 14-3-3 C-terminal loop in ligand interaction. Proteins 49: 321-325, 2002.

TZIVION G, AVRUCH J: 14-3-3 proteins: active cofactors in cellular regulation by serine/threonine phosphorylation. J Biol Chem 277: 3061-3064, 2002.

VAN HEUSDEN GP, YDE STEENSMA H: Yeast 14-3-3 proteins. Yeast 23: 159-171, 2006.

VEISOVA D, REZABKOVA L, STEPANEK M, NOVOTNA P, HERMAN P, VECER J, OBSIL T, OBSILOVA V: The C-terminal segment of yeast BMH proteins exhibits different structure compared to other 14-3-3 protein isoforms. Biochemistry 49: 3853-3861, 2010.

VEISOVA D, MACAKOVA E, REZABKOVA L, SULC M, VACHA P, SYCHROVA H, OBSIL T, OBSILOVA V: Role of individual phosphorylation sites for the 14-3-3-protein-dependent activation of yeast neutral trehalase Nth1. Biochem J 443: 663-670, 2012.

WANG B, YANG H, LIU YC, JELINEK T, ZHANG L, RUOSLAHTI E, FU H: Isolation of high-affinity peptide antagonists of 14-3-3 proteins by phage display. Biochemistry 38: 12499-12504, 1999.

WARD RJ, MILLIGAN G: A key serine for the GTPase-activating protein function of regulator of G protein signaling proteins is not a general target for 14-3-3 interactions. Mol Pharmacol 68: 1821-1830, 2005.

WATSON N, LINDER ME, DRUEY KM, KEHRL JH, BLUMER KJ: RGS family members: GTPase-activating proteins for heterotrimeric G-protein alpha-subunits. Nature 383: 172-175, 1996.

WILLARDSON BM, WILKINS JF, YOSHIDA T, BITENSKY MW: Regulation of phosducin phosphorylation in retinal rods by Ca2+/calmodulin-dependent adenylyl cyclase. Proc Natl Acad Sci USA 93: 1475-1479, 1996.

XIAO B, SMERDON SJ, JONES DH, DODSON GG, SONEJI Y, AITKEN A, GAMBLIN SJ: Structure of a 14-3-3 protein and implications for coordination of multiple signalling pathways. Nature 376: 188-191, 1995.

YAFFE MB, RITTINGER K, VOLINIA S, CARON PR, AITKEN A, LEFFERS H, GAMBLIN SJ, SMERDON SJ, CANTLEY LC: The structural basis for 14-3-3: phosphopeptide binding specificity. Cell 91: 961-971, 1997.

YAFFE MB: How do 14-3-3 proteins work?-- Gatekeeper phosphorylation and the molecular anvil hypothesis. FEBS Lett 513: 53-57, 2002.

ZHU X, CRAFT CM: Interaction of phosducin and phosducin isoforms with a 26S proteasomal subunit, SUG1. Mol Vis 4: 13, 1998.

ZHU X, CRAFT CM: Modulation of CRX transactivation activity by phosducin isoforms. Mol Cell Biol 20: 5216$5226,2000$. 